\title{
CONTRA LA MITIFICACIÓN DE INTERNET. UNA APROXIMACIÓN ALA TENSIÓN ENTRE UN IMAGINARIO MERCANTIL Y UN IMAGINARIO COMPARTIDO EN INTERNET
}

\author{
AGAINST INTERNET SUBLIME. AN APPROACH TO \\ COMMODIFICATION AND SHARING IN THE INTERNET
}

Rafael Rodríguez Prieto

Recibido: octubre de 2012

Universidad Pablo de Olavide de Sevilla

Aceptado: diciembre de 2012

[rrodpri@upo.es]

Palabras clave: Poder, derechos civiles, mercantilización, dominación, Internet.

Keywords: Power, civil rights, domination, commodification, Internet.

Resumen: Una batalla por el control de Internet se produce a diario ante nuestros ojos. La gente está cansada de que la falta de acción de gobiernos y la arrogancia de los proveedores posibilite que el futuro de la información pueda quedar en manos de estos últimos al construir las redes a imagen y semejanza de sus intereses. Internet puede ser positivo en el sentido del acceso a información relevante en la comunidad y más allá de ella. Internet ha sido una relevante herramienta para desarrollar el cambio político en el mundo. Internet es también relevante para el desarrollo económico y las comunicaciones. Pero puede ser también negativo. Hoy las reglas de las autopistas de la información se realizan por las corporaciones globales con poca supervisión pública. Internet puede ser utilizado para controlar a los ciudadanos. Internet es cada vez más una herramienta usada por megacorporaciones para apropiarse y controlar lo que debería ser propiedad pública, pero de hecho puede terminar siendo propiedad privada. La alternativa es desarrollar Internet como una herramienta cooperativa, común y libre.

Abstract: A battle is raging for control of the Internet and it is taking place every day. People fed up with the recalcitrance and outright arrogance of their providers and governments' lack of action are taking their information future into their own hands by building their own high-speed networks. The internet can be positive in the sense that important information can be reached throughout community and beyond that. The Internet has been a very remarkable tool in order to develop political change around the world. The Internet is a powerful tool to spread economic development and communications. But it can also be negative. 
Today the rules of the information highway are made by a handful of global corporations with little public oversight. The Internet can be used in order to monitor citizens. The internet is about big companies owning and controlling so much of what should public property, but in fact the entire internet could be a private property. The alternative is to develop the Internet as a cooperative, common, free tool.

\section{Introducción: Internet como campo de batalla}

Si existe un campo de batalla político en nuestros días ése es Internet ${ }^{1}$. En y por Internet se están dirimiendo las principales luchas sociopolíticas y económicas que marcarán el futuro del mundo. Vivimos en una cierta Edad Media sociotecnológica, si queremos expresarlo así. No decimos esto porque estemos en periodo de oscuridad o de falta de comodidades -al menos para una parte minoritaria del mundo-. No, utilizamos esta idea con un cierto paralelismo histórico, esquivando, en la medida de lo posible, un desdichado anacronismo. De acuerdo a historiadores como E. P. Thompson o Marc Bloch, la Edad Media fue un periodo histórico de intensas luchas sociales y políticas de clase. Durante este tiempo los señores trataron de privatizar y cercar los bienes comunales, fundamento de la libertad popular. ${ }^{2}$.

1 Este trabajo forma parte del I+D DER 201021420 del MEC. En el artículo se desarrollan conceptos e ideas de dos trabajos anteriores: Censura digital y protección de derechos. ¿Hacia una restricción de contenidos y derechos en Internet? y Un análisis de la censura digital y sus alternativas. Los casos de Guifi.net y Democracia 4.0 (ambos inéditos).

2 Doménech, A., Prólogo a Thompson, E. P., $L a$ formación de la clase obrera en Inglaterra, Capitán Swing, Madrid, 2012, p. 15.
La mercantilización de la tierra, el trabajo y el dinero resultante de las fuerzas capitalistas fue respondida por lo que Thompson denominó una economía moral de la multitud, que eran un conjunto de normas, prácticas y valores compartidos por aquellos que eran despojados de bienes comunes $^{3}$. Este proceso aparece ligado a toda una lucha popular en Inglaterra por el derecho a obtener el sufragio que se extenderá por los siglos posteriores a la revolución inglesa, tal y como historiadores como Anthony Arblaster han puesto de manifiesto, al estudiar las propuestas de los levellers frente a los terratenientes ${ }^{4}$. En este sentido, como señala Hill, existieron dos revoluciones en la Inglaterra de mitad del siglo XVII: una que tuvo éxito y estableció los derechos de propiedad y dio poder político a los propietarios y otra de la que hubo conatos y que postulaba la propiedad comunal y la democracia, cuyo fin era acabar con la Iglesia estatal y la ética protestante ${ }^{5}$. El triunfo de la primera convierten los cercamientos en un "deber patriótico", llegándose a una definitiva

\section{Id.}

4 Arblaster, A., Democracia, Alianza, Madrid, 1992 , p. 45 y ss.

5 Hill, C., El mundo trastornado. El ideario popular extremista en la revolución inglesa del siglo XVII, Siglo XXI, Madrid 1983, p. 4. 
rendición de cuentas entre la agricultura tradicional y la capitalista 6 .

La "tierra" de la que hablamos carece de cualquier relación con la producción agrícola o con características de orden geológico. Tampoco se trata de una tierra exclusivamente "virtual". Internet es también un cuerpo físico; con sus nodos y sus redes tangibles de comunicación. Eso sí: Internet abre todo un espacio de posibilidades colonizables y abiertas a su explotación o desarrollo. Algunos hablan de Internet, como de "un nuevo mundo". No estamos seguros ni de que se trate de una exageración o de una percepción ajustada a la realidad. De lo que sí estamos convencidos es de que Internet y el proceso que lleva aparejado, conlleva toda una concepción de las relaciones sociales, productivas o humanas.

Internet puede ser caracterizado, a partir de la definición que de espacio hace Milton Santos, como un espacio poblado por un conjunto indisoluble de sistemas de objetos y acciones ${ }^{7}$. El uso de esta definición conlleva situar Internet bajo un prisma distinto al tradicional. Con esta noción buscamos un estudio del espacio cibernético que implique repensar tanto interrelaciones como prácticas propias de la dinámica social, lo que conlleva el análisis de las conexiones entre procesos de transformación de estructuras sociales y las personas que actúan en dicho espacio. Desde la concepción de Santos, el espacio es donde confluyen relaciones de interdependencia, funcionales, de selección, de reproducción, de sustitución o de

6 Simplicio, O., Las revueltas campesinas en Europa, Crítica, Barcelona, 1989, p. 66.

7 Santos, M., La naturaleza del espacio. Técnica y tiempo. Razón y emoción, Ariel, Barcelona, 2000, p. 19. cambio. Su actuación se refleja en diversas escalas, niveles y tiempos. Tomando la idea más general de Santos, la dinámica socioterritorial de Internet está ligada a las manifestaciones, procesos y articulaciones de los sistemas sociales. El espacio se recrea dinámica y permanentemente como un conjunto indisoluble, solidario y contradictorio de sistemas de objetos y sistemas de acciones no considerados de forma aislada, sino en un contexto histórico. Los sistemas de objetos condicionan las acciones, pero al mismo tiempo los sistemas de acciones generan nuevos objetos o influyen sobre los preexistentes, lo que provoca que el espacio se encuentre en una transformación constante ${ }^{8}$. Cuando la sociedad actúa sobre el espacio de Internet lo hace sobre objetos como realidad social o siguiendo la idea general de Santos, "como formas-contenidos (...) objetos sociales ya valorizados a los cuales la sociedad busca ofrecer o imponer un nuevo valor"9.

Internet es una forma contenido donde los procesos de transformación de una totalidad sufren modificaciones en su estructura a causa de la dinámica social, el impacto de sus acciones y de las configuraciones materiales -su cuerpo físicoy territoriales y de la división del trabajo. Internet, como espacio cibernético, es un generador de símbolos, sentidos y significados condicionados por el tiempo. Este espacio es soporte de flujos horizontales que impulsan lo común, lo compartido o cooperativo, pero también de flujos verticales que nutren las tendencias utilitaristas e individualistas. En este punto, el análisis del poder y del dominio adquiere una centralidad difícilmente cuestiona-

8 Id., pp. 54-55.

9 Id., p. 91. 
ble. En las próximas líneas realizaremos un breve análisis sobre la conexión entre poder e Internet. Posteriormente, estudiaremos la consolidación de un imaginario mercantilizador/privatizador, fruto de la consolidación y extensión de relaciones de dominio a través de la red. Finalmente expondremos brevemente las posibilidades de ruptura con dicho imaginario.

\section{Campo de batalla Internet. Poder, dominio y tendencias en la red.}

Identificar el poder, las relaciones de poder o el dominio no es una tarea fácil. Cuando uno otea desde el puente de Waterloo los nuevos rascacielos erguidos sobre el vetusto paisaje del antiguo Londres, entiende cómo los procesos construyen la realidad. Las manifestaciones añejas del poder como la Torre de Londres o el propio edificio del parlamento han dado paso a edificios de cristal de formas innovadoras, construidos durante la era de los productos financieros derivados $^{10}$. Lo apabullante de la nueva arquitectura londinense es proporcional a la influencia de la city en las políticas de sus

10 Sobre esta interesante conexión existe una nutrida bibliografía. Podemos mencionar Meyer, J. F., Myths in Stone, University of California Press, London, 2001, pp. 58 y ss. Su análisis en la parte del libro indicada se centra en Pekín y en la Alemania nazi. Otro texto que recomendamos es Sudjic, D., La arquitectura del poder. Cómo los ricos y poderosos dan forma a nuestro mundo, Ariel, Barcelona, 2007, pp. 143-167. En esta parte del trabajo el autor estudia la arquitectura del nuevo laborismo (la cúpula del milenio) o el parlamento de Escocia. Para Sudjic el gobierno laborista continuó con una idea del thatcherismo porque ningún gobierno como el de Blair fue tan consciente de la "imaginería del poder" (p. 151). gobiernos. En diciembre de 2011 David Cameron se negó a suscribir los cambios en el tratado de Lisboa porque no consiguió garantías de que el sector financiero local no se vería afectado por la futura regulación financiera que se apruebe en Bruselas. Este hecho no debería pasar inadvertido y muestra la influencia de las entidades financieras en las políticas de Downing Street ${ }^{11}$.

Pero no siempre es tan sencillo identificar la influencia de poderes y la posibilidad que relaciones de poder pasen a ser de dominio. Podemos seguir la descripción de Weber de los tipos de dominación y el estudio de aquella, fundamentada en un conjunto de reglas abstractas creadora de un orden impersonal de carácter racional, o la que inventa un panóptico donde interiorizamos la necesidad de identificarnos con un orden a través de la evaluación constante de nuestros actos y los de los otros $^{12}$. Las cosas no parecen ser del todo claras. Al contrario. El grado de complejidad que alcanza el poder, sus dinámicas y el establecimiento de relaciones de dominio y su análisis no es una tarea fácil.

Cuando el objeto de nuestro estudio es Internet y los desafíos que presenta en el campo de la siempre difícil protección de Derechos Fundamentales, todo parece hacerse más complejo. Desde el comienzo de Internet hemos escuchado tanto las voces de aquellos que denunciaban sus peligros y áreas oscuras como los que se situaban en el polo opuesto y lo sublimaban como el medio de comunicación que arreglaría, poco más o menos, todos

$11 \mathrm{http} / / / w w w . e l e c o n o m i s t a . e s / e c o n o m i a / n o t i-$ cias/3613382/12/11/la-city-se-divide-anteel-veto-de-cameron.html

12 Bravo, V., Figuraciones del poder y la ironía, Monte Ávila Editores, Caracas, 1997, p. 33 y 42. 
los problemas del mundo. Internet se ha presentado como el medio que uniría personas, que derrumbaría fronteras y desarrollaría países. A esta realidad alternativa a la real y cotidiana se ha denominado la promesa de lo sublime ${ }^{13}$. La tecnología no es inmune a la mitificación. Cuando estudiamos Internet debemos hacerlo con rigor y cuidado, analizando los procesos socioeconómicos, culturales y políticos que conforman la tecnología. Internet es mucho más que una foto fija que estudiar o una plataforma neutral en la que, de vez en cuando, surgen problemas.

El mundo de la tecnología o de la sociedad de la información es un reflejo de la sociedad material. Para los que cuestionan el optimismo tecnológico Internet podría convertirse en la materialización tecnológica del poder en red, cuyo fin es vertebrar los procesos de dominación y control social propiciados por la racionalidad política y económica del capitalismo ${ }^{14}$. Este poder en red es defendido de acuerdo a algunas características originales y otras tradicionales del poder soberano, consistente en reprimir resistencias e imponer una cierta idea de orden global; además está conectada con la comunicación sin comunicabilidad de Agamben o las críticas que McChesney realiza a la organización de las estructuras de comunicación regidas por grandes oligopolios ${ }^{15}$.

La veracidad de esta visión se ha visto favorecida por una estrategia de concentra-

13 Mosco, V., The Digital Sublime. Mith, Power and Cyberspace, MIT Press, Cambridge, 2004, pp. 3-5.

14 V. Celorio, M., Internet y Dominación. Hacia una sociología de la nueva espacialidad, Plaza y Valdés, México, 2011, p. 51.

15 Hardt, M., Negri, A., Multitud: guerra y democracia en la era del Imperio, Debate, Madrid, 2007, p. 57. ción empresarial a nivel mundial auspiciada por la desregulación estatal y la fijación de agenda e información digital. Según Mariana Velorio, esta estrategia cuenta con tres etapas: una primera se sitúa en la década de los ochenta, la segunda en los noventa y la tercera comienza en el siglo XXI. Al comienzo de los ochenta los grupos eran monomedia y con una baja diversificación. Aunque existían alianzas y colaboraciones cada empresa trabajaba por cuenta propia. Esta situación cambió en los 90 con la fusión entre Time y Warner y la configuración de cuatro conglomerados que dotan de contenidos informativos y de entretenimiento al mundo: Westinghouse Electric Corp compra CBS, Walt Disney compra Capital Cities y ABC, Time Warner compra Turner Broadcasting System, propietaria de CNN, Viacom compra Paramount, Blockbuster y CBS y amplían las cadenas de News CO. La tercera etapa se define por la compra de AOL por Time Warner y de Seagram Universal por Vivendi. La tendencia que acompaña la concentración de estos capitales es presionar a las autoridades nacionales para que reglamentar y tarifar el ancho de banda, limitar la capacidad de diseminar información y de tráfico según el pago que se haga del servicio ${ }^{16}$.

Ambas posiciones deben ser analizadas. Probablemente encontremos en cada una de ella argumentos para el optimismo o el pesimismo. Internet, aunque atravesado por corrientes privatizadoras/mercantilizadoras evidentes, es aún un campo de batalla entre diversas tendencias: aquellas que privilegian lo plural, diverso, abierto, horizontal y común o las corrientes proclives a limitar el acceso y la neutralidad de

16 Celorio, M., Internet y Dominación. Hacia una sociología de la nueva especialidad, op. cit., p. 75. 
la red o privilegian la concentración y la restricción en la libertad de los ciudadanos. Junto con las concentraciones mencionadas, coexisten también prácticas con resultados muy relevantes. Iniciativas que aportan creatividad como guifi.net o la influencia de diversas redes sociales en la emergencia de movilizaciones sociales como las acaecidas en el norte de África o en España, Israel o EE.UU. Sería igual de apresurado decir que todo es represivo, mercantilizador/privatizador y disciplinario, como liberador, común, abierto y creativo. Lo que no dudamos es que Internet es ahora mismo un gran campo abierto donde conviven diversidad de tendencias y donde los ciudadanos actúan y se implican cada vez más. La significación de Internet como medio de desarrollo político y participativo es una de las manifestaciones más exitosamente difundidas en la opinión pública.

Para los optimistas tecnológicos Internet no sólo es una herramienta tecnológica que facilita la vida de los ciudadanos y ayuda al comercio y al desarrollo económico, sino también un instrumento contra las dictaduras y difusor de la democracia. Con motivo de la denominada por los medios de comunicación "Primavera árabe", se ha subrayado el poder de convocatoria de las redes sociales a través de Internet y el impacto político que han tenido en la movilización. Al mismo tiempo, en Siria la represión de régimen y su bloqueo informativo ha sido superada a través de vídeos de móviles colgados en Youtube. Sin embargo para los pesimistas estos acontecimientos no son tan halagüeños como parece.

Morozov, considera que es necesario llevar a cabo una evaluación seria de Internet como instrumento contra el autoritarismo. El autor pone varios ejemplos, entre los que destaca Irán. Es necesario cuestionar tanto el ciberutopismo, como la centralidad de Internet. Es más: Internet puede aumentar el control de regímenes autoritarios. Un exceso de fetichismo de la tecnología como modo de cambio del mundo es peligroso para la promoción real de la democracia ${ }^{17}$. Es imprescindible analizar un objeto de estudio en ciencias sociales contextualizándolo. Nuestra visión será fragmentaria si no nos cuestionamos las condiciones, económicas, políticas, culturales o sociales en las que se producen, en las que se desarrollan.

Es cierto que existe una gran potencialidad movilizadota en las redes sociales, pero no deja de ser menos verdadero que estas redes son empresas privadas, donde los usuarios firman un contrato que en la mayoría de las ocasiones ni siquiera leen y cuyos servidores suelen estar fuera de las fronteras del país. Algunos críticos de ensalzar demasiado el protagonismo de las redes sociales han señalado que se corre el riesgo de quedarse en lo virtual y convertir a Twitter en un moderno muro de los lamentos, cuya acción termina a la vez que comienza un partido de fútbol ${ }^{18}$. Es cierto que Twitter puede ayudar a difundir una manifestación o encuentro, pero su impacto social no creemos que vaya mucho más allá, en especial por las propias características del servicio. La conexión entre seguidores y seguidos genera un "ecosistema" especial en donde el usuario puede tener una sensación errónea de la movilización social en su conjunto. Además, los debates que se suscitan en

17 Morozov, E., The Net Delusion. How not to Liberate the World, Allen Lane, London, 2011, pp. 27,30 y 313 .

18 http://www.elconfidencial.com/alma-corazonvida/2012/04/16/twitter-propaga-la-protesta-ciudadana-o-acaba-con-ella-96028/. 
la red social van alternándose a velocidades vertiginosas y la calidad de los mismos también. Se puede pasar de debatir en una misma tarde sobre las conexiones entre políticos que pasan al mundo empresarial y sus implicaciones -la famosa "puerta giratoria"- a las últimas declaraciones del entrenador del At.de Madrid.

Los servicios que ofrece y ofrecerá Internet pueden ser una magnífica oportunidad para fortalecer derechos como la libertad de expresión, la participación en política o la educación, entre otros. Sin embargo, tantas innovaciones y mejoras no tienen lugar en el vacío. Todas estas transformaciones se insertan en un contexto específico y determinante: el mundo de principios del siglo XXI. Las sociedades distribuidas por todo el planeta se encuentran más interconectadas que nunca gracias a la tecnología a la que hemos hecho referencia. Esta tecnología permite que las dictaduras tengan cada vez más difícil hurtar información al pueblo que someten o que en los poblados de zonas desérticas de África se puedan seguir las series y telenovelas que relatan historias de lujo, sexo y violencia que animan a los individuos que habitan tales parajes a intentar el sueño europeo en un cayuco o una patera.

En este mismo mundo persisten dictaduras que de acuerdo con grandes corporaciones censuran contenidos en la red o una desigualdad planetaria entre individuos que no deja de crecer, lo que dificulta el acceso de ingentes porciones de la población no sólo a los avances tecnológicos, sino a las más elementales bases para la subsistencia (comida, agua, salud, educación). No hace mucho, se asomaba a las pantallas de nuestros televisores las manifestaciones y protestas en Siria. Gracias a las nuevas tecnologías se pudo burlar la censura y mostrar al mundo la crueldad de su régimen dictatorial. También sucedió lo mismo en el caso de Birmania, cuando ciudadanos de diversas partes del planeta pudieron observar horrorizados desde sus hogares la brutalidad con que unos gobernantes reprimían las protestas de la población civil apoyada por los monjes budistas. No obstante, semanas después casi nadie recordaba Birmania. Ha desaparecido de los televisores o de la mayoría de los periódicos y nada parece haber cambiado. En Siria puede suceder algo semejante. El mero conocimiento de una situación no es suficiente para cambiarla.

Pero junto a las posibilidades que ofrecen las redes sociales de burlar la censura de los gobiernos podemos identificar un lado oscuro y preocupante. Empresas privadas como Google, Facebook, Youtube o Twitter censuran contenidos para llegar acuerdos con gobiernos totalitarios. La decisión más reciente ha sido la de Twitter, quien decidió restringir los tweets en países específicos si infringían las leyes locales, lo que suscitó acusaciones de censura por parte de los miembros de IFEX Reporteros sin Fronteras (RSF), el Centro de Bahrein por los Derechos Humanos (BCHR) y la Egyptian Organization for Human Rights (Organización Egipcia por los Derechos Humanos, EOHR). Antes, Twitter tenía que eliminar un tweet de toda su red si recibía una solicitud de retirada de un Gobierno. Pero la empresa dijo en una publicación en su blog el 26 de enero de 2012 que ahora tiene la capacidad de bloquear selectivamente un tweet para que no aparezca para los usuarios de un país ${ }^{19}$. El

19 Publicado por http://www.periodistas-es. org/libertad-de-expresion/censura-en-internetpolitica-de-twitter-que-restringe-tweets-suscitaindignacion. 
ejercicio de un netpower o poder en red por parte de corporaciones privadas es un hecho poco analizado. A través del mismo pueden arrogarse facultades que tradicionalmente eran patrimonio de los gobiernos y sujetas a los tribunales de justicia. La censura selectiva en redes sociales, el rastreo e intromisión en cuentas personales, el bullying o el trolling constituyen graves ataques además a la privacidad de los ciudadanos ${ }^{20}$. La consolidación de redes sociales que son usadas como si fueran públicas, pero cuya titularidad es privada, conlleva la aceptación de cláusulas abusivas que implican problemas de seguridad jurídica que afectan a los Derechos Fundamentales. Una persona puede verse censurada sin tener medios efectivos para reparar su derecho a la libertad de expresión. Dicha censura puede tener como consecuencia vulneraciones del derecho a la tutela judicial efectiva. Citemos algún ejemplo.

El caso del robo de datos a PlayStation Network es paradigmático y ejemplifica con claridad nuestro argumento. En abril de 2011 unos ciberdelicuentes robaron los datos de más de setenta millones de clientes del servicio de Sony Playstation Network. Entre los datos sustraídos se encontraba información tanto personal como bancaria. Los más de tres millones de usuarios afectados por el ataque al servicio PlayStation Network padecieron además un grave menoscabo en sus derechos, ya que no pudieron interponer una demanda a Sony. Esta compañía almacena toda la información en servidores estadounidenses por lo que la Agencia de Protección de Datos (AEPD) no pudo investigar el caso porque toda la informa-

20 V. Iván, D., Centralización, censura e Internet en Etcétera http://www.etcetera.com.mx/articulo.php?articulo=11558. ción se encontraba en servidores extranjeros ${ }^{21}$. Esta deslocalización del elemento material o corpóreo de la red es un aspecto al que debemos prestar atención con desarrollos como la "nube". El cloud computing que ofrecen algunas empresas implica desafíos de orden jurídico muy importante y que además pueden afectar al derecho a la protección de datos 22 o a la jurisdicción donde se resuelvan los conflictos y los costes que pueda tener para el usuario ${ }^{23}$.

Pero los peligros de control y mal uso de Internet no sólo implica a las grandes corporaciones o a regímenes totalitarios. Hace unos meses los principales medios europeos recogían en sus boletines de noticias que el gobierno de Alemania estaba espiando a sus ciudadanos gracias a un troyano con que infectaban los ordenadores. El colectivo de Hackers denunciante analizó un programa, supuestamente utilizado por funcionarios de las administraciones alemanas, para espiar las comunicaciones a través de Internet de los ciudadanos $^{24}$. Los sistemas de filtrado y cribado de información son un elemento preocupante al que pocas veces se presta atención suponen una erosión muy grave

$21 \mathrm{http} / /$ www.publico.es/ciencias/373265/sonyreconoce-el-robo-de-datos-de-tres-millones-deespanoles.

22 Sobre este tema resulta muy ilustrativo el informe elaborado por el Consejo de la Abogacía Española sobre el uso del cloud computing por despachos de abogados. En este sentido resulta muy útil el siguiente estudio: V. http://www. abogados.es/portalABOGADOS/archivos/fiche$\operatorname{ros} / 1340036756670$.pdf.

23 Una norma de muy dudosa constitucionalidad en España como la Patriot Act podría ser aplicable si los usuarios tienen que litigar ante la jurisdicción estadounidense.

$24 \mathrm{http} / /$ www.spiegel.de/international/germany/ 0,1518,790944,00.html. 
del Estado de Derecho. Alemania es el último de algunos ejemplos que implican un aprovechamiento de gobiernos de las posibilidades disciplinarias y represivas de Internet. Redes como Echelon, dirigida por oficinas de espionaje EE.UU., Gran Bretaña, Canadá o Autralia, Enfopol -un sistema de interceptación de comunicaciones de la UE-, Carnivore -un software espía desarrollado por el FBI, compatible con Windows, u OSEMINTI- un software espía desarrollado por España, Francia e Italia, suponen amenazas ciertas a la privacidad de las personas ${ }^{25}$. En prolijas ocasiones, las autoridades gubernamentales acuden a la seguridad interior del país para justificar este tipo de comportamientos. El problema reside en la falta de control judicial de dichas actividades, lo que pone en una situación muy difícil a la protección de los derechos de los ciudadanos.

Es evidente que la relación entre poderInternet-relaciones de dominio puede ser especialmente conflictiva. Pero no es suficiente con conocer estos síntomas. Nuestro objetivo es ir más allá. Tratar de comprender los procesos que generan estos preocupantes síntomas. De hecho, como defendíamos al comienzo del trabajo, la tensión entre tendencias privatizadoras y liberadoras es una de la grandes características de la red de hoy. En el siguiente epígrafe analizaremos este proceso de restricciones de contendidos y justificaremos teóricamente la emergencia conformación de un imaginario al que denominamos Dictanet. Analizaremos sus características fundamentales.

25 V. Celorio, M., Internet y Dominación. Hacia una sociología de la nueva especialidad, op. cit., p. 75 y ss.

\section{Dictanet. Concepto y características}

¿Qué es Dictanet? ¿Existe Dictanet? ¿Cómo se ha desarrollado? ¿Qué consecuencias tiene? Estamos seguros que estas preguntas y otras muchas son pertinentes. Parece obvio que la construcción etimológica de Dictanet es sencilla. La unión entre dictadura e Internet. ¿Es tan grave lo que puede pasar en Internet para relacionar ambos términos? Existen síntomas que nos hacen pensar en amenazas sobre las bases que sustentan Internet y que se resumen en la libertad de comunicar e intercambiar contenidos, opiniones o ideas. Por supuesto Internet es más que eso todavía, pero una definición mínima como la que presentamos nos ayudará para caracterizar Dictanet.

Estos desafíos son síntomas de un conjunto de tendencias constituyen lo que denominamos censura digital. Este tipo de censura esta constituida por una serie de restricciones de contenidos que a su vez generan una serie de tendencias que constituyen Dictanet. Las restricciones podrían resumirse en el siguiente cuadro:

R1: Restricción a la libertad de acceso.

R2: Restricción a libertad de intercambio y comunicación.

R3: Restricción a la tutela judicial efectiva.

R4: Restricción a la creatividad político, social y económica.

Estas restricciones de contenidos se resumen en dos tendencias fundamentales que conforman el marco de análisis que proponemos con el nombre de Dictanet:

T1: Tendencia al control sobre el acceso a la información y sobre los contenidos. 
Esta tendencia englobaría el conjunto de las restricciones a las que hemos hecho referencia.

T2: Tendencia a la construcción de un universo simbólico monocultural.

Esta tendencia se ocuparía de la construcción del imaginario simbólico de Dictanet centrado en la privatización y en la mercantilización de contenidos y acciones.

Antes de proseguir es imprescindible realizar una precisión de orden metodológico: Dictanet no existe. Dictanet es un proceso más que una realidad consolidada. Es un conjunto de tendencias interaccionadas que, ya sea de forma concertada o no, limitan, reducen o liquidan la construcción de espacios de intercambio comunes, democráticos y cooperativos.

La interacción entre estas tendencias implica un proceso al que denominamos Dictanet, cuyo fundamento filosófico se sustenta en un proceso de cosificación y mercantilización capitalista de Internet. Este enfoque filosófico de la red está gobernado por un conjunto de valores que actúan de tal forma que reproduzcan en Internet la hegemonía vigente en el resto de áreas de la realidad. Uno de las tensiones que más relevancia alcanza en Internet es la dirección ideológica y cultural. Yochai Benkler considera que Internet es hoy en día lo que es gracias a un conjunto de personas y colectivos que generaron información sin derechos de propiedad; sin ellos, que eligieron compartir libremente sus creaciones, la revolución en marcha hubiera sido imposible ${ }^{26}$.

Existe multitud de bibliografía de gran interés en torno a Internet y sus beneficios o amenazas. Libros como los de Jonathan

26 Benkler, Y., The Wealth of Networks, Yale University Press, New Haven, 2007, p. 472.
Zittrain, Rebecca Mackinnon o Jeff Chester nos muestran síntomas preocupantes de una realidad en construcción -la cibersociedad, o como quiera denominársela-. Estos autores realizan análisis muy interesantes que ponen de manifiesto los peligros que enfrenta la red. En algunos casos se presentan incluso alternativas. El problema de estas aproximaciones es que no existe un tratamiento sistemático de las raíces de los problemas; los procesos y causas que ocasionan las restricciones de contenidos que conforman lo que denominamos censura digital. Los autores mencionados señalan los peligros de que el acceso a Internet esté controlado por unas pocas compañías, por ejemplo. Esas compañías pueden liquidar lo que se ha venido en llamar neutralidad en la red. ¿Hasta que punto es un fenómeno diferente a las evidentes tendencias de concentración empresarial en otros sectores? Estamos convencidos que es imprescindible un análisis concienzudo de los procesos y las causas reales de los problemas; no podemos analizar los efectos como si fueran las causas; o la situación en Internet como un proceso divorciado del conjunto de al realidad socioeconómica existente. No se puede ignorar las conexiones, ni la complejidad de la sociedad. Nuestro análisis es deudor de la economía política de la comunicación de Vincent Mosco y de autores de enfoque materialista.

Internet comenzó como una red en la que se prohibía expresamente el comercio. En los últimos años ha pasado a ser algo básicamente comercial. No queremos decir con esto que Internet no pueda ser usado como una herramienta de desarrollo económico. Pero reducir Internet a un objeto cuyo fin es vendernos algo significaría un empobrecimiento de la red y de los altos objetivos con los que fue concebida. 
En un artículo sobre historia de Internet de Foster y McChesney se resalta que Internet fue una creación del sector público financiada por la recaudación de impuestos pagados por contribuyentes. Antes de 1990 el ente estadounidense que desarrolló Internet -the National Science Foundation Network- limitó explícitamente la red a usos no comerciales. Esta política interna se sustentaba en la idea de que la esfera pública democrática y el comercio no deberían mezclase. Sin embargo, la carencia de un debate serio y la hegemonía imparable del neoliberalismo hizo que con la retórica del mercado libre se invadiera por las corporaciones la red $^{27}$.

Foster y McChesney ponen el dedo en la llaga cuando afirman que se careció de un debate serio sobre dónde se quería llevar Internet. Ese debate aún no existe. Sabemos mucho de los "planes de negocio" de corporaciones en los que incluyen su estrategia con Internet, pero sabemos poco o nada de objetivos sociales. Ésa es sin duda una de las carencias esenciales: se han sustituido los fines sociales y el debate en común de la gente por planes de negocio. Este hecho nos devuelve a una de las principales preocupaciones sobre Internet a la que nos hemos referido anteriormente: la falta de instrumentos regulatorios que limiten la proliferación de delitos o la protección de datos personales. La falta de un debate serio está en la raíz de estos síntomas. Ese debate riguroso está omitido en la mayoría de los análisis. Se abandona todo a una cierta mano invisible cibernética que al final pondrá las cosas en su sitio. Esta propuesta sustentaría un libre mercado de ideas tecnopolíticas.

27 Bellamy Foster, J., McChesney, R., "The Internet's Un holy Marriage to Capitalism", Monthy Review, V. 62, n 10.
Pero las cosas no son así en el mundo real. El "libre mercado de ideas" es una construcción sobre la libertad de expresión política que tuvo un gran éxito en las formulaciones realizadas en EE.UU. sobre la Primera Enmienda y el derecho a al libertad de expresión. El idealismo y la carga de ficción que conlleva esta asunción se traslada a Internet en la forma de adaptar Internet a imaginario simbólico de pensamiento económico neoclásico. Justo lo que sucede con la libertad de expresión, desde esta perspectiva. Este tipo de transposición podría generar graves problemas en la protección de las personas frente a las grandes empresas. Expliquemos por qué.

Muy unido al punto anteriormente expuesto está la batalla por la hegemonía. Como hemos señalado Internet es también un campo de batalla ideológico y cultural. Jamás debemos olvidar que en Internet es reflejo y continuidad de las tensiones de todo orden que se dan en el mundo no virtual. Internet no es ajeno a todo ello. De hecho, en los últimos meses se nos ha presentado Internet y, en concreto las redes sociales, como generadores de grandes movilizaciones que han conseguido cambiar regímenes y gobiernos. Como señalamos en el epígrafe anterior, constantemente se apela a Twitter o Facebook como instrumentos para unir esfuerzos y desarrollar alternativas políticas de movilización social. Movimientos como el 15M, Occupy o los desarrollados en Israel o países de mayoría musulmana se han ayudado de las redes sociales para sus estrategias. Más tarde nos ocuparemos de este fenómeno en el contexto del imaginario de Dictanet. Solo expresar de momento que es necesario ser rigurosos y cuidadosos al analizar el impacto político de las movilizaciones que se gestan en 
redes sociales. Debemos huir de la sublimación o idealización y centrarnos en los datos con los que contamos.

El otro elemento preocupante es la asunción acrítica en la red de valores conectados con la hegemonía vigente. Internet es un campo privilegiado para el estudio de una contemporánea "guerra de posiciones" de la que nos hablaba Gramsci. Lo colectivo, lo común, las condiciones materiales y las relaciones de dominación quedan subordinadas u ocultas en un enfoque idealista e individualista que se trata de trasladar a Internet. A este enfoque lo denominamos como tecno-

darwinismo social. Esta perspectiva se sirve del imaginario de Internet como un espacio en que las ideas se contrastan y la competencia corregirá por sí sola las ideas equivocadas, haciendo triunfar a las verdaderas, guiadas por una mano invisible del mercado de las ideas. Alimenta la idea del lobo solitario que intercambia ideas y posiciones, que al final tiene éxito al arrastrar a otros usuarios que desde sus casas y sus teclados comparten ideas o creencias o las enfrentan en la red.

Internet ha sido pensado desarrollado como un espacio cooperativo y común. Esto significa que el propio medio es en sí mismo tanto una herramienta cooperativa como un bien común cuyas raíces filosóficas se sustentan en una línea de pensamiento radicalmente opuesta al neocontractualismo hegemónico. Este hecho supone que Internet no sólo haya entrado en un proceso de mercantilización capitalista al que hemos aludido anteriormente, sino además en concebirlo como una herramienta de consolidación a nivel ideológico cultural de los valores que promueve el neoliberalismo. Estos valores se difunden de diversas maneras y por diferentes vías. Internet se ha convertido en un medio de comunicación privilegiado a fin de insertar en la mente de sus usuarios estos valores. De nuevo el capitalismo es capaz de revertir un medio que en principio, sería contrario a sus intereses en un objeto a su favor. De este hecho no se habla mucho, pero el nivel axiológico y de guerra de posiciones configura otro de los pilares de Dictanet. Promover lo privado, frente a lo común; el aislacionismo, frente a lo colectivo, la maximización del beneficio frente a compartir. Internet como espacio compartido es una idea fuerza a la que Dictanet es refractaria.

En último lugar debemos hablar de Dictanet como "oasis político". Internet tiene una gran proyección a nivel de movilización política como hemos señalado. El problema es que Internet sirva como un punto de fuga; como una mera protesta que por la propia aceleración de la realidad y la ingente cantidad de información se vaya solapando y no genere ningún tipo de alternativa política consolidad. Dictanet, desde el punto de vista político, sería un espacio en el que descargar frustraciones. Un instrumento de satisfacción psicológica inmediata cuando tomamos conciencia de alguna injusticia. Un espacio en el que miles de comentaristas o tertulianos emiten opiniones que pueden generar un estado de opinión que nunca va más allá de las fronteras cibernéticas porque difícilmente se traduce en una movilización real en la calle; cuando ésta se produce se carece de la organización necesaria y del esfuerzo y dirección para alcanzar unos fines. No es aventurado decir que existe una sublimación de Internet y de lo que representa en el activismo político. Los resultados prácticos hasta el momento de un nuevo tipo de movimiento social donde se integra directamente Internet no están siendo tan fructíferos 
como cabía esperar. Tampoco podemos rechazar esta movilización. No se trata de ello. Simplemente ser conscientes que Dictanet también puede ser una forma de encauzar la indignación social en una dirección inofensiva para el orden establecido.

Las características de Dictanet como proceso abierto y en construcción serían por tanto:

a) Dictanet es un instrumento metodológico para analizar las principales tendencias en Internet contradictorias con los objetivos para lo que fue concebido.

b) Dictanet es también la reconceptualización de Internet como espacio de desarrollo de los valores del capitalismo tanto en el orden socioeconómico como en el simbólico.

c) Dictanet es también un instrumento que puede anular la movilización sociopolítica de los ciudadanos.

Estas características nos ayudan a comprender Internet, no como una realidad consolidada y acabada, sino como un objeto de estudio dinámico y en proceso de mutación, de acuerdo con las tendencias que se dan y las luchas a las que estamos asistiendo en todos los planos y que influyen sobre Internet. En el siguiente epígrafe profundizaremos en este proceso y analizaremos las características que hemos presentado en esta parte del trabajo.

\section{I. Dictanet. Las tendencias}

Dictanet es un proceso constituido por tendencias privatizadoras de control, por una lucha por la hegemonía en la dirección ideológica y cultural y una forma de reforzar el conformismo social. Este proceso se encuentra en marcha. Dictanet no es una realidad consolidada. Dictanet es una categoría de análisis; una herramienta metodológica para estudiar Internet de una forma radicalmente distinta a como se ha hecho hasta ahora.

Junto con Dictanet, en Intenet hay otro proceso al que denominamos Freenet y que exploraremos en la parte final de este trabajo. Este proceso cuenta con una serie de tendencias antagónicas a la de Dictanet. Los conceptos de Dictanet y Freenet son tipos ideales en el sentido weberiano, es decir no son categorías que definan una realidad concreta, más que eso son haces de características que describen los puntos terminales. Nuestra proposición se basa en el establecimiento de un modelo de análisis para contemplar la disposición del poder en la red en un espacio geográfico determinado. De esta manera, Dictanet o Freenet no están en un sitio concreto, son categorías de análisis que nos sirven para acceder al esquema de poder en un sitio dado, éstas se presentarán hibridadas en un mismo espacio, así en una realidad se podrán apreciar rasgos de Dictanet y de Freenet. Esto no sólo nos permite ver una foto fija, sino que también permite analizar una dimensión diacrónica, pudiendo establecerse tendencias e inclinaciones, por lo tanto también podríamos encuadrar nuestro enfoque dentro de los análisis procesuales.

Lo que es relevante es la necesidad de estudiar Internet como un proceso el que se dan un conjunto de tendencias que van conformando una realidad social y cibernética, sobre la base de una conjunto de restricciones a las que anteriormente hemos hecho referencia. En el caso de Dictanet, estas tendencias se pueden resumir en los siguientes puntos: 
T1: Tendencia al control sobre el acceso a la información y sobre los contenidos.

T2: Tendencia a la construcción de un universo simbólico monocultural.

Ambas tendencias se encuentran interconectadas entre sí y son el producto de las restricciones de contenidos aludidas. No es posible estudiarlas aisladas. El proceso de Dictanet es una pararealidad en construcción que tiene como espejo las relaciones de dominio sociopolíticas, económicas y culturales del mundo no cibernético. Es un error establecer una separación radical entre Internet y el resto de la sociedad, pero no es menos erróneo caer en la naturalización de Internet.

Con naturalización de Internet queremos decir que se toma Internet como un soporte neutral. La tecnología es política; se desarrolla por grupos determinados con fines específicos. Como señala David Noble, tradicionalmente la tecnología se ha construido como una fuerza inocente cuyos imperativos provienen de fuentes apolíticas y neutrales. La tecnología no es el problema, ni la solución. Debemos trascender la mistificación tecnológica del poder en nuestra sociedad, que viene un consolidado sentido común que en palabras de Mumford se resumía en el maridaje entre un constante progreso tecnológico y un beneficio sin fin e ilimitado. Las amenazas a los que nos enfrentamos no provienen de las políticas tecnológicas sino porque hipnotizados por la ideología del progreso hemos sustituido tecnología por política ${ }^{28}$. Mosco señala que con el surgiendo de la tecnología digital y el neoliberalismo las normas y jerarquías que gobiernan los procesos de la hegemonía

28 Noble, D., Present tense technology, http:// faculty.unlv.edu/wjsmith/smithtest/NOBLE.pdf pp. 139, 142, 148. capitalista tienen a ser ocultados y los procesos en sí se mistifican como resultado de la elección individual ${ }^{29}$.

Zittrain distingue entre aparatos que permitan al usuario crear aplicaciones (generative devices), desarrollar protocolos, compartir conocimiento e información de forma bidireccional y aquellos que tienen un propósito tasado (non generative devices). El propio Zittrain define generatividad como "la capacidad de un sistema de producir un cambio no anticipado mediante contribuciones no filtradas de amplias y variadas audiencias". Zittrain incluye en esta posibilidad tanto plataformas de software abierto, como Windows. Los cambios siempre se hacen a través de las compañías que los comercializan y la información es unidireccional: solo fluye en el sentido del productor al consumidor. Entre los primeros, Zittrain sitúa a los ordenadores y a Internet. Entre los segundos estarían aparatos como una consola, una cámara de vídeo o un IPad ${ }^{30}$. No es que uno sea malo y otro bueno -cada uno puede tener su público y se debiera mantener un cierto equilibrio-, pero Zittrain tiene reservas en lo que se refiere a la seguridad.

Este tipo de distinciones pueden ser interesantes, pero se quedan en la superficie. Primero, porque se da por sentado que Internet es en sí un medio en el que se genera creatividad. Es posible que eso sea así, pero también puede suceder lo contrario como sucede en el proceso al que denominamos Dictanet. La segunda parte del problema proviene de no tener en cuenta las relaciones de poder y do-

29 V. Mosco, V., The Digital Sublime, op. cit.

30 V. Zittrain, J., The Future of the Internet and How to Stop It, Yale University Press, New Haven, 2008.

Revista Internacional de Pensamiento Político - I Época - Vol. 7 - 2012 - [173-191] - ISSN 1885-589X 
minio que se generan en el ámbito tecnológico. ¿Cuál es la causa del auge de los productos cerrados o que no generan intercambio o creatividad en términos de Zittrain? Esa es la cuestión. Pero preguntarse por ello implica explorar las relaciones de poder en el interior de los procesos tecnológicos. El historiador David Noble y su famoso trabajo sobre el luditas muestra una interpretación diferente sobre este movimiento. Los luditas trataron de combatir el intento del capitalismo de imponer nuevas formas de control sobre los trabajadores, al mismo tiempo que se les limitaba su conocimiento. Este es el aspecto que nos interesa ahora resaltar. En las categorías que maneja Zittrain se no muestra la diferenciación entre aparatos generadores y no generadores, pero no se profundiza en la intencionalidad política de desarrollar este tipo de aparatos que implican un empobrecimiento de las habilidades y conocimientos del destinatario de esos productos.

En el caso de Internet hay autores que reclaman el potencial de la red y de la tecnología como una forma de liberalización de relaciones de dominio gracias al conocimiento. Las oportunidades de la economía de la sociedad de la información residen en que la actividad intelectual humana o trabajo inmaterial es mucho más decisivo que la propiedad de los medios materiales de producción. Se establece una dependencia de la actividad intelectual humana, lo que hace prescindible la figura del capitalista como inversor o propietario de los medios de producción, una suerte de economía colectivista de la información ${ }^{31}$.

31 Pla López, R., La naturaleza del capitalismo, en http://www.uv.es/ pla/naturcap.htm.
Conviene recordar que en la segunda revolución industrial se da una paradoja semejante con el caso de los obreros más especializados, como los ingenieros. Para Noble en la segunda revolución industrial los aspectos técnicos y capitalistas del trabajo del ingeniero eran dos caras de una misma moneda: la tecnología moderna. Como tales, raras veces, por no decir ninguna, eran distinguibles: las demandas técnicas sólo definían las posibilidades capitalistas en la medida en que las demandas capitalistas definían las posibilidades técnicas"32. Confinar la innovación o el desarrollo tecnológico dentro de los márgenes capitalistas es un elemento que no puede pasarse por alto en el análisis de Internet.

En el imaginario de Dictanet los límites a la creatividad de los usuarios no son como defiende Zittrain una opción dentro del sistema, sino es el sistema en sí. El capitalismo trata por todo los medios de acomodar la herramienta tecnológica -Internet- a sus dispositivos ideológicos. Como en la segunda revolución industrial, la paradoja de obreros especializados capaces de socavar el modelo capitalista se trata de cortocircuitar desde la misma lógica capitalista, es decir las demandas de Internet sólo deben definir o en su mayoría contener posibilidades capitalistas de interacción, a la vez que las demandas y necesidades capitalistas definen las posibilidades y opciones del propio instrumento: Internet.

En el pasado reciente, un buen número de usuarios sabía programar. Aunque fuese en un lenguaje sencillo como Basic, no faltaban usuarios familiarizados con el

$32 \mathrm{~V}$. Noble D., El diseño de Estados Unidos, $\mathrm{M}^{\circ}$ Trabajo y Seguridad Social, Madrid, 1987, pp. 34 y ss. 
lenguaje. Incluso se enseñaba en los institutos de secundaria y en la relación entre computadoras y sujetos el peso de la programación era relevante. Hoy en día, el panorama ha cambiado mucho. Son muy pocos los usuarios que saben o se interesan. Es como si hubiésemos aprendido a leer y hablar, pero no a escribir. Con ello no queremos decir que tenga que ser obligatorio saber programar; lo que estamos es poniendo de manifiesto una tendencia que limita las habilidades de los usuarios. Este límite lleva aparejado un auge sin precedente de dispositivos cerrados -teléfonos inteligentes, sin ir más lejos-. Este tipo de dispositivo es antagónico de lo que anteriormente describíamos. Pero sería un error decir que es una opción. Es una tendencia que tiene el mismo ADN que el propio modelo de relaciones sociales o de racionalidad que se desea imponer.

Las diferentes tendencias enumeradas anteriormente se explican desde este proceso. Los límites a la accesibilidad, la libertad de expresión e intercambio de información, el derecho a la tutela judicial efectiva o la limitación de la creatividad sociopolítica, económica o cultural. Estas restricciones no se pueden estudiar de forma superficial y contextualizada. Se encuentran interconectadas y no se pueden separar de los proceso sociales donde tienen lugar, ni del pensamiento hegemónico que sirve de sustento y fundamentación. Estas manifestaciones del imaginario de Dictanet no son pacíficas. Entre los propios agentes existen intereses que pueden llegar a ser conflictivos. Por ejemplo las rivalidades entre grandes empresas cuyo negocio es Internet. Dictanet es un proceso, con diversas aristas. Las tendencias marcan las directrices con las que el capitalismo adapta nuevamente la tecnología a sus necesidades. Ya suce- dió en las anteriores revoluciones industriales y el objetivo en este momento del proceso histórico es hacer lo mismo en la sociedad de la información. Internet es el gran campo de batalla de nuestros días.

El proceso que conforma lo que denominamos el imaginario de Dictanet es la vía por la que el capitalismo reordena la sociedad del conocimiento para que se adapte a las necesidades del capitalismo. En este proceso concurre también una no menos decisiva "guerra de maniobras" -en el sentido gramsciano del término- en la que Dictanet precisa establecer una serie de valores o creencias que faciliten el proceso. Esta lucha es el proceso a través del cual un bloque tecnopolítico de intereses, ideas, creencias o racionalidad vigoriza su presencia en las instituciones adaptando la correlación de fuerzas en el tejido social correspondiente al uso de una tecnología, en este caso Internet. Pero como señalamos al principio de este estudio, Internet es un verdadero campo de batalla porque existen tendencias antagónicas en lucha. En el último epígrafe expondremos las características del imaginario antagónico a Dictanet, al que denominamos Freenet, es decir, una visión de Internet como espacio compartido y común. Esta idea es un punto de partida desde el que desarrollar nuevas investigaciones.

\section{Freenet como corriente antagonista. Alqunas ideas para sequir trabajando.}

Freenet es un imaginario en construcción. Se puede entender tanto como una reacción a Dictanet, como un proceso abierto y cooperativo que responde a los orígenes de la red como plataforma del intercam- 
bio de conocimiento, como señalaron McChesney y Foster ${ }^{33}$. Como hemos señalado, Internet es sobre todo un espacio nuevo, abierto a un sinfín de posibilidades y actuaciones. Los desafíos que se plantean con el nacimiento de la red y sus desarrollos en el contexto del imaginario de Freenet son menores en la medida que la realidad "de fuera" en sus inicios no intervino en el ciberespacio. La hegemonía en construcción se sustenta en valores cooperativos, comunes y de intercambio de conocimiento e ideas. Es en la medida que esta pararealidad se las ve con la no cibernética, es cuando se producen fricciones que otorgan a Freenet otro tipo de desafíos que implican una reacción frente a "cuerpos y valores extraños" a las ideas con las que se estaba cimentando Internet. El auge de Internet como plataforma enfocada al negocio de forma extrema sitúa los valores del capitalismo radical actual en confrontación con otros valores, como la cooperación o la reivindicación de lo compartido en espacios comunes.

Estos desafíos son síntomas de un conjunto de tendencias constituyen lo que denominamos apertura digital. Este tipo de apertura esta constituida por una serie de desarrollos de contenidos que a su vez generan una serie de tendencias que constituyen Freenet. Los desarrollos podrían resumirse en el siguiente cuadro:

R1: Desarrollo de la libertad de acceso.

R2: Desarrollo de la libertad de intercambio y comunicación.

R3: Desarrollo de la tutela judicial efectiva.

R4: Desarrollo de la creatividad político, social y económica.

33 Bellamy Foster, J., McChesney, R., "The Internet's Un holy Marriage to Capitalism”, op. cit.
Tales desarrollos de contenidos se resumen en dos tendencias fundamentales que conforman el marco de análisis que proponemos con el nombre de Freenet:

T1: Tendencia la apertura en el acceso común a la información y sobre los contenidos.

T2: Tendencia a la construcción de un universo simbólico diverso y cooperativo.

Ambas tendencias se encuentran interconectadas entre sí y son el producto de los desarrollos de contenidos aludidas. No es posible estudiarlas aisladas. El proceso de Freenet es una pararealidad en construcción que colisiona con las relaciones de dominio sociopolíticas, económicas y culturales del mundo no cibernético y nutre la lucha de fuerzas hegemónicas críticas al orden geopolítico y socioecnómico actual. Freenet es alimentado por estas fuerzas y a su vez las potencia y fortaleza porque Internet continúa siendo un territorio en disputa; un campo de lucha en que las fuerzas de uno y otro sentido están colisionando. Como afirmamos en el caso de Dictanet, es un error establecer una separación radical entre Internet y el resto de la sociedad, pero no es menos erróneo caer en la naturalización de Internet.

Los procesos a favor del software libre, la neutralidad en la red, la imposición de límites a la propiedad intelectual, contra el control que pretenden ejercer gobiernos y grandes corporaciones forman parte de la lucha a la que aludimos. Como en la Europa medieval, las tendencias privatizadoras de la tierra se enfrentan a fuerzas que pretenden evitarlo a través del mantenimiento de una tierra común. Lo común y lo privado se enfrentan siglos después en una lucha de consecuencias económicas, políticas y socioculturales. Somos espec- 
tadores de excepción de una batalla que tendrá consecuencias radicales en la conformación de los valores e ideas y en la política y economía de los años venideros. De su resultado depende no sólo Internet, sino el conjunto de la sociedad.

Debemos replantear la idea de control en el contexto actual. Ya no es posible mantener viejas aproximaciones. El control se ha refinado. Si el que realizaban los Estados era preocupante, con la revolución tecnológica se han descubierto herramientas desarrolladas por entes privados que son igual o más peligrosos. Internet ha jugado un papel muy relevante en la consolidación de este control informal, pero altamente eficaz. Éste es ejercido por empresas a las que los mismos consumidores les abren la puerta. Se da la paradoja de que son los propios usuarios los que posibilitan ese control. Los ciudadanos invierten una gran parte de su capital social, de su tiempo en este cibermundo, lo que financia a las empresas y, por tanto, profundiza en el control.

Desde un punto de vista económico los bienes de consumo tecnológico son los que más rápido se han depreciado en la historia, a la vez que requieren una inversión alta con el fin de evitar una obsolescencia casi inmediata del bien comprado. Crean además una tecnodependencia. La extimidad potencia el imaginario de Dictanet. Hoy en día, la indefensión de un usuario medio en Internet es casi medieval. La mercantilización y privatización de la red es un proceso evidente. Freenet es un imaginario antagónico a éste cuyo producción se concentra en lo compartido, lo común y cooperativo. El intercambio de conocimiento e información, como la construcción poliédrica de creencias, ideas y mensajes es desarrollada a través de procesos no finalistas, pero que apun- tan a una reconstrucción/transformación de la sociedad capitalista. Este tipo social no es asumible desde esta posición. Los procesos que son fruto directo de este imaginario colisionan y van en una dirección distinta al del aparato simbólico capitalista. Se trata de una tensión irresoluble. Desde la perspectiva intelectual, debemos contar con herramientas que nos permitan analizar estos procesos. Es insuficiente el mero estudio de síntomas privatizadores, controladores o aperturistas y compartidos.

Ni Dictanet, ni Freenet son realidades consolidadas. Vivimos un tiempo fascinante para el análisis de un fenómeno que cambiará formas de relación y construcción de imaginarios sociales. Pero no nos engañemos. Revertir Dictanet o impulsar Freenet no es un esfuerzo centralizado en el mundo cibernético, sino un trabajo desde el mundo cibernético y en cooperación con las acciones materiales y concretas en el resto de los espacios sociales. Como respuesta a estas tendencias mercantilizadotas y privatizadoras emerge Freenet, como desarrollo de un cuerpo de Internet abierto y común, a la vez que participativo. En los próximos años asistiremos a más episodios de esta batalla.

\section{Bibliografía}

Bravo, V. (1997): Figuraciones del poder y la ironía, Monte Ávila Editores, Caracas.

Ceballos Garibay H. (2000): Foucault y el poder, Coyoacán, México DF.

Celorio, M. (2011): Internet y Dominación. Hacia una sociología de la nueva espacialidad, Plaza y Valdés, México.

Chester, J. (2007): Digital Destiny. New Media and the Future of Democracy, The New Press, New York. 
Cotino Hueso, L. (ed.) (2011): Libertades de expresión e información en Internet y las redes sociales: ejercicio, amenazas y garantías, PUV, Valencia.

Deleuze, G.(1986): Foucault, Paidós, Buenos Aires.

Foucault, M. (2003): Hay que defender la sociedad, Akal, Madrid.

Foucault, M; (1991): Historia de la sexualidad. La voluntad de saber, vol I, Siglo XXI, Madrid.

Foucault, M. (1980): Microfísica del poder, La Piqueta, Madrid,.

Hardt, M., Negri, A. (2007): Multitud: guerra y democracia en la era del Imperio, Debate, Madrid.

Iván, D., Centralización, censura e Internet en Etcétera http://www.etcetera.com. $\mathrm{mx} /$ articulo.php?articulo $=11558$

Lessig, L. (2008): REMIX: Making Art and Commerce Thrive in the Hybrid Economy, New York, The Penguin Press.

Lukes, S. (1985): El poder. Un enfoque radical, Siglo XXI, Madrid.
Meyer, J. F. (2001): Myths in Stone, University of California Press, London. ,

Morozov, E.(2011): The Net Delusion. How not to Liberate the World, Allen Lane, London.

Mosco, V. (2009): The Political Economy of Communication, London, Sage.

Mosco, V. (2006), "La economía política de la comunicación: una actualización diez años después", Cuadernos de Información y Comunicación, vol. 11.

Mosco, V. (2004): The Digital Sublime. Mith, Power and Cyberspace, MIT Press, Cambridge.

Sudjic, D. (2007): La arquitectura del poder. Cómo los ricos y poderosos dan forma a nuestro mundo, Ariel, Barcelona.

Villate, J. (2001): "Libertad de expresión en Internet". Disponible en el ARCHIVO del Observatorio para la CiberSociedad en http://www.cibersociedad.net/archivo/ articulo. php?art=37.

VV.AA.(1993): Disparen sobre Foucault, El cielo por Asalto, Buenos Aires. 